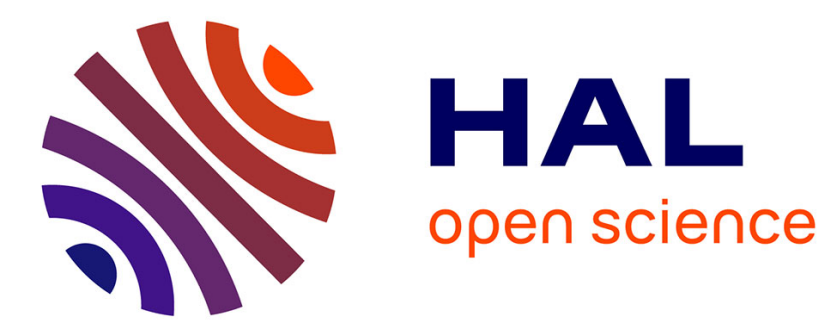

\title{
PHASE TRANSITIONS IN COUPLED SPIN SYSTEMS
}

\author{
Serge Galam, M. Gabay
}

\section{To cite this version:}

Serge Galam, M. Gabay. PHASE TRANSITIONS IN COUPLED SPIN SYSTEMS. Journal de Physique Colloques, 1988, 49 (C8), pp.C8-1547-C8-1548. 10.1051/jphyscol:19888708 . jpa-00228945

\section{HAL Id: jpa-00228945 https://hal.science/jpa-00228945}

Submitted on 1 Jan 1988

HAL is a multi-disciplinary open access archive for the deposit and dissemination of scientific research documents, whether they are published or not. The documents may come from teaching and research institutions in France or abroad, or from public or private research centers.
L'archive ouverte pluridisciplinaire HAL, est destinée au dépôt et à la diffusion de documents scientifiques de niveau recherche, publiés ou non, émanant des établissements d'enseignement et de recherche français ou étrangers, des laboratoires publics ou privés. 


\title{
PHASE TRANSITIONS IN COUPLED SPIN SYSTEMS
}

\author{
S. Galam $\left({ }^{1}\right)$ and M. Gabay $\left({ }^{2}\right)$ \\ $\left.{ }^{1}\right)$ Département de Recherches Physiques, Tour 22-E.3, Université P. et M. Curie, 75252 Paris Cedex 05, \\ France \\ $\left({ }^{2}\right)$ Laboratoire de Physique des Solides, Université Paris-Sud, 91405 Orsay, France
}

\begin{abstract}
A simple coupled spin model is presented to describe the phase diagram of plastic crystals. Translational and rotational degrees of freedom are associated respectively with a lattice-gaz Hamiltonian and a $q$-Potts Hamiltonian. A tetralinear coupling between rotations and translations is considered. Effects of adding random fields which couple solely to the Potts variables are studied.
\end{abstract}

Plastic crystals are characterized by the coexistence of translational long range order with rotational disorder in a thermodynamically stable phase [1]. This phase (the plastic phase) occurs between the solid and liquid phases via two first order transitions.

While a lot of effort has been devoted to the study of the plastic phase itself [1] not much attention has been paid to the construction of the global phase diagram of plastic crystals. To address this problem a coupled spin system of two Ising sets has been presented recently [2].

In this note we present an improved version of the model of reference [2]. Translational and rotational degrees of freedom are associated with respectively lattice-gaz variables and $q$-Potts variables. A tetralinear coupling is introduced between translations and rotations. Effects of adding random fields are studied.

To each molecule $i$ we associate a lattice-gaz variable $t_{i}$ and a $q$-Potts variable $\sigma_{i}$. A solid state corresponds to $t_{i}=1$, a liquid state is represented by $t_{i}=0$. In parallel, $\sigma_{i}$ describes the $q$ equivalent discrete orientations which result from the combined symmetries of both the lattice and the molecule. For instance $q=6$ in the case of $\mathrm{C}\left(\mathrm{CH}_{3}\right)_{4}$. In the following we will use new Potts variables $r_{i}^{\sigma}$ defined as:

$$
r_{i}^{\sigma}=\frac{q \delta^{\sigma_{i} \sigma}-1}{q-1}
$$

where $\delta^{\sigma_{i} \sigma}=1$ if $\sigma_{i}=\sigma$ or zero otherwise.

Taking a Potts Hamiltonian [3] for the $\left\{\sigma_{i}\right\}$ we start with the bare Hamiltonian:

$$
H_{0}=-J_{t} \sum_{\langle i, j\rangle} t_{i} t_{j}-J_{r} \frac{q-1}{q} \sum_{\substack{\langle i, j\rangle \\ \sigma}} r_{i}^{\sigma} r_{j}^{\sigma}
$$

where $J_{t}>0$ and $\langle i, j\rangle$ denotes a summation over nearest neighbor (nn) pairs.

We now introduce a tetralinear coupling of the form:

$$
H_{\mathrm{c}}=-\alpha \sum_{\langle i, j\rangle} t_{i} r_{i}^{1} t_{j} r_{j}^{1}
$$

where $\alpha>0$. The choice of equation (3) is dictated by the experimental fact that translational long range order is correlated to the spontaneous rotational ordering and thus favors a particular orientation denoted here by 1 . Terms similar to equation (3) have been used to study different physical problems $[4,5]$.

Writting $\varphi_{i}=2 t_{i}-1$, the two order parameters are $m=\left\langle r_{i}^{1}\right\rangle$ and $\varphi=\left\langle\varphi_{i}\right\rangle$. Performing a mean field treatment of the Hamiltonian $H_{0}+H_{c}$ gives two first order transitions with three phases which are $(m \neq 0$, $\varphi \neq 0),(m=0, \varphi \neq 0)$ and $(m=\varphi=0)$. The transitions are respectively associated to the latticegaz (high temperature) and to the Potts (low temperature) transitions. The effect of the tetralinear coupling is first to increase the temperature range of rotational order by inducing one effective stronger coupling among the $\left\{r_{i}^{\sigma}\right\} J_{r}^{\prime}=J_{r} \frac{q-1}{q}+\alpha t^{2}$, where $\left\langle t_{i}\right\rangle=t$. In parallel it decreases the melting temperature to $k T_{\mathrm{c}}^{t}=$ $c J_{t}$ with respect to $k T_{\text {co }}^{T}=c\left(J_{t}+\alpha\right)$ which corresponds to the case without rotational degrees of freedom, i.e., $r_{i}^{1}=1$. Details of the calculations will be published elsewhere [6].

The existence of the intermediate phase $(m=0, \varphi \neq$ 0 ) which corresponds to the plastic phase depends on the assumption $J_{t} \gg J_{r}$. While such constraint makes sense in the case of ionic crystals it is wrong in the case of molecular crystals for which interactions being of the Van der Walls type, $J_{t} \sim J_{r}$. To extend our model to molecular crystals we invoke the rotational hypothesis $[7,8]$ used to justify the model of reference [2]. The existence of rotational states, i.e., free rotations with long relaxation times is equivalent within our static approach to introduce quenched random fields coupled solely to the rotational degrees of freedom $[7,8]$. To implement this hypothẹsis we add the Hamiltonian:

$$
H_{R}=-\sum_{i, \sigma} H_{i}^{\sigma} r_{i}^{\sigma}
$$

where $H_{i}^{\sigma}$ is a quenched random field which favors the $\sigma$-orientation of the $i$-molecule. The effect of the 
random fields is in particular to generate an effective $J_{r}^{\mathrm{e}} \ll J_{t}[6,9]$.

At this stage we obtained a different description of the plastic phase for respectively ionic crystals and moleculars crystals: rotational states occur in the last group and not in the first one. Such a feature could be checked using molecular dynamics.

[1] Ed. J. N. Sherwood, The plastically crystalline state (Wiley, New York) 1979.

[2] Galam, S., Phys. Lett. A 122 (1987) 271.
[3] Potts, R. B., Proc. Cambridge Philos. Soc. 48 (1952) 106.

[4] Berker, A. N., Ostlund, S. and Putnam, F. A., Phys. Rev. B 17 (1978) 3650.

[5] Vause, C. A. and Walker, J. S., Phys. Lett. A 90 (1982) 419.

[6] Galam, S. and Gabay, M., preprint (1988).

[7] Galam, S., Phase Transitions (in press).

[8] Michel, K. H., Phys. Rev. B 35 (1987) 1405.

[9] Blankschtein, D., Shapir, Y. and Aharony, A., Phys. Rev. B 29 (1984) 1263. 